ISSN 1984-3372

http://portaldeperiodicos.unisul.br/index.php/EeN/index

\title{
ESTRATÉGIAS QUE AGREGAM VALOR NOS SEGMENTOS DO AGRONEGÓCIO NO BRASIL: UM ESTUDO DESCRITIVO
}

\section{STRATEGIES THAT ADD VALUE IN AGRIBUSINESS SEGMENTS IN BRAZIL: A DESCRIPTIVE STUDY}

\section{LAS ESTRATEGIAS QUE AGREGAN VALOR EN LOS SECTORES DE LA AGROINDUSTRIA EN BRASIL: UN ESTUDIO DESCRIPTIVO}

\section{Tamires Camargo Soares}

Curso de especialização em Analise de Viabilidade de Investimento pela Fundação Getulio Vargas - Online (2012); MBA em Gestão de Produção (2014)

Endereço: UTFPR, Campus Cornélio Procópio. Av. Alberto Carazzai, n. 1640, Centro, CEP 86300000 . Cornélio Procópio, PR, Brasil

Telefone: (43) 35204057

E-mail: tamires.camargo.soares@gmail.com

\section{Márcio Jacometti}

Doutor em Administração pela Universidade Federal do Paraná

Professor do Ensino Básico, Técnico e Tecnológico da UTFPR/Campus Cornélio Procópio

Endereço: UTFPR, Campus Cornélio Procópio. Av. Alberto Carazzai, n. 1640, Centro, CEP 86300000 . Cornélio

Procópio, PR, Brasil

Telefone: (43) 35204057

E-mail: jacometti@utfpr.edu.br

Artigo recebido em 03/03/2015. Revisado por pares em 30/06/2015. Reformulado em 21/10/2015. Recomendado para publicação em 21/11/2015 por Ademar Dutra (Editor Científico). Publicado em 30/12/2016. Avaliado pelo Sistema double blind review.
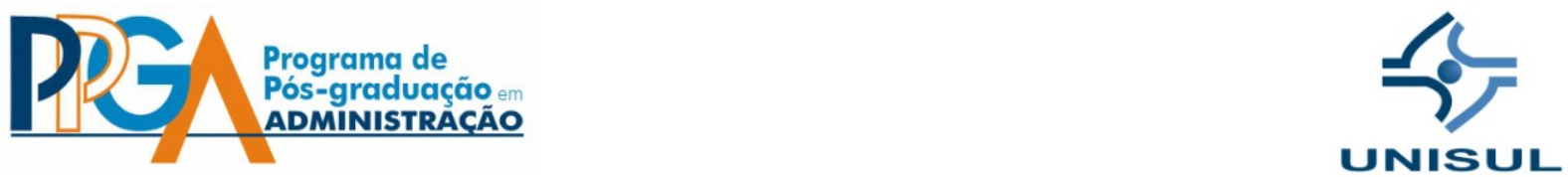


\section{RESUMO}

O agronegócio tem importância vital para a economia brasileira e a identificação das estratégias presentes nesse segmento, mediante uma abordagem fundamentada em casos reais, boas práticas e indicadores de qualidade revela-se pertinente. $O$ objetivo deste artigo foi analisar quais estratégias de negócio agregaram valor ao agronegócio no Brasil, a partir do ano 2000, considerando variáveis macroeconômicas. Trata-se de uma pesquisa exploratória, que teve como método a descrição de casos baseada na análise de dados secundários, fundamentada em referencial teórico sobre estratégias competitivas do modelo porteriano e análise do ambiente de negócios via modelo SWOT.

Palavras-chave: Estratégias competitivas; Cadeia de valor; Análise SWOT; Agronegócio.

\section{ABSTRACT}

Agribusiness is vitally important to the Brazilian economy and the identification of strategies in this segment, through an approach based on real cases, best practices and quality indicators appears relevant. The aim of this study was to analyze which business strategies add value to agribusiness in Brazil, from 2000, considering macroeconomic variables. This is an exploratory research which had as method description of cases based on the analysis of secondary data, grounded on theoretical framework on competitive strategies of the model by Porter and business environment analysis via SWOT model.

Keywords: Competitive strategies; Value chain; SWOT analysis; Agribusiness.

\section{RESUMEN}

La agroindustria es de vital importancia para la economía brasileña y la identificación de estas estrategias en este segmento, a través de un enfoque basado en casos reales, las mejores prácticas y los indicadores de calidad resulta ser relevante. El objetivo de este estudio fue analizar las estrategias de negocio añaden valor a la agroindustria en Brasil, a partir de 2000, teniendo en cuenta las variables macroeconómicas. Se trata de una investigación exploratoria, que tenía el método de la descripción de casos basados en el análisis de datos secundarios, basado en un marco teórico sobre las estrategias competitivas del modelo porteriano y análisis del entorno empresarial a través del modelo SWOT.

Palabras clave: Estrategias competitivas; Cadena de valor; Análisis SWOT; Agroindustria. 


\section{INTRODUÇÃO}

A presente pesquisa buscou identificar as estratégias utilizadas no segmento do agronegócio brasileiro, que contempla uma ampla cadeia produtiva, abrangendo desde o preparo da terra para o cultivo até a agroindústria, incluindo a distribuição da produção que chega ao consumidor final. Portanto, o tema Estratégias que agregam valor nos segmentos do agronegócio no Brasil é desenvolvido por meio desta identificação, tendo como pano de fundo uma análise macroeconômica (BLANCHARD, 2011) e suas influências sobre este setor.

A pesquisa investigou, também, as ameaças e oportunidades do ambiente, bem como as forças e fraquezas do setor, avaliando como estas estratégias influenciaram a otimização dos processos e a implementação de boas práticas de qualidade. Tal abordagem leva em conta o trabalho de Chandler (1962), que desenvolveu a análise SWOT, e o de Porter (1989), que apresentou as cinco forças competitivas para a análise estratégica.

O levantamento de dados e informações do mercado possibilita maior compreensão do fenômeno. No que tange à abordagem macroeconômica, a pesquisa considera estudos de cenários, demandas de mercado e suas influências diretas no segmento do agronegócio, que é fortemente impactado pela política econômica governamental, como a definição das taxas de juros e de câmbio, pelos efeitos da inflação e da política tributária sobre a produção.

Assim, este trabalho tem por objetivo analisar quais foram as estratégias de negócio que agregaram valor ao setor de agronegócios no Brasil a partir do ano 2000. Para tanto, foram identificadas as estratégias que seguiram uma política de qualidade, e avaliado como tais estratégias influenciaram a lucratividade do agronegócio no Brasil, no período observado pela pesquisa.

\subsection{CONSIDERAÇÕES METODOLÓGICAS}

Para atingir o objetivo, o presente estudo adotou a técnica de pesquisa exploratória, onde o trabalho de análise desenvolveu-se com base em estudo de casos (práticas estratégicas observadas no mercado). A bibliografia utilizada parte dos estudos de Porter (1989), que apresentou as cinco forças competitivas para a análise estratégica; 
Chandler (1962), com seu brilhante trabalho sobre análise SWOT; e Araújo (2007) e Mendes (2007), que focaram prioritariamente o agronegócio.

O estudo foi predominantemente descritivo, buscando analisar a amplitude de um determinado fenômeno, suas variáveis e a compreensão dos fatos pertinentes ao objeto da pesquisa, envolvendo as áreas de gestão estratégica, qualidade e macroeconomia. A pesquisa teve caráter qualitativo e exploratório, mas utilizou dados históricos quantitativos ao levantar índices e outros parâmetros por meio da coleta de dados de livros, jornais, revistas e instituições de pesquisa e apoio ligadas ao universo do agronegócio, como o Centro de Estudos Avançados em Economia Aplicada (Cepea), o Ministério do Desenvolvimento Indústria e Comércio Exterior (MDIC), a Companhia Nacional de Abastecimento (Conab), entre outros.

De modo geral, vale ressaltar que o estudo foi estruturado com o propósito de analisar quais estratégias agregaram valor ao setor de agronegócio no Brasil, a partir do ano 2000.

\section{CONCEITO DE AGRONEGÓCIO}

O termo agronegócio é a tradução de agribusiness e refere-se ao conjunto de atividades vinculadas com a agropecuária (BACHA, 2004). O agronegócio é uma agregação de atividades divididas em, no mínimo, quatro segmentos, compreendendo os fornecedores de insumos; as atividades que gravitam em torno da agropecuária; os processos de transformação da agroindústria; as operações de armazenagem, transporte e distribuição.

Cada um destes segmentos assume funções próprias e específicas, que compõem um elo importante em todo o processo produtivo e comercial. Ainda sobre esta conceituação é possível por meio de uma sistematização, visualizar de maneira clara estas divisões, conforme mostra a figura 1.

O agronegócio configura um segmento de importância vital para a economia brasileira, pois, além de gerar emprego e renda, o setor tem contribuído fortemente para a estabilidade macroeconômica, ajudando a amenizar o déficit comercial oriundo de outros setores produtivos (GASQUES et al., 2004).

Revista Eletrônica de Estratégia \& Negócios, Florianópolis, v.8, n.3, set./dez. 2015. 
Figura 1 - Sistematização do Agronegócio

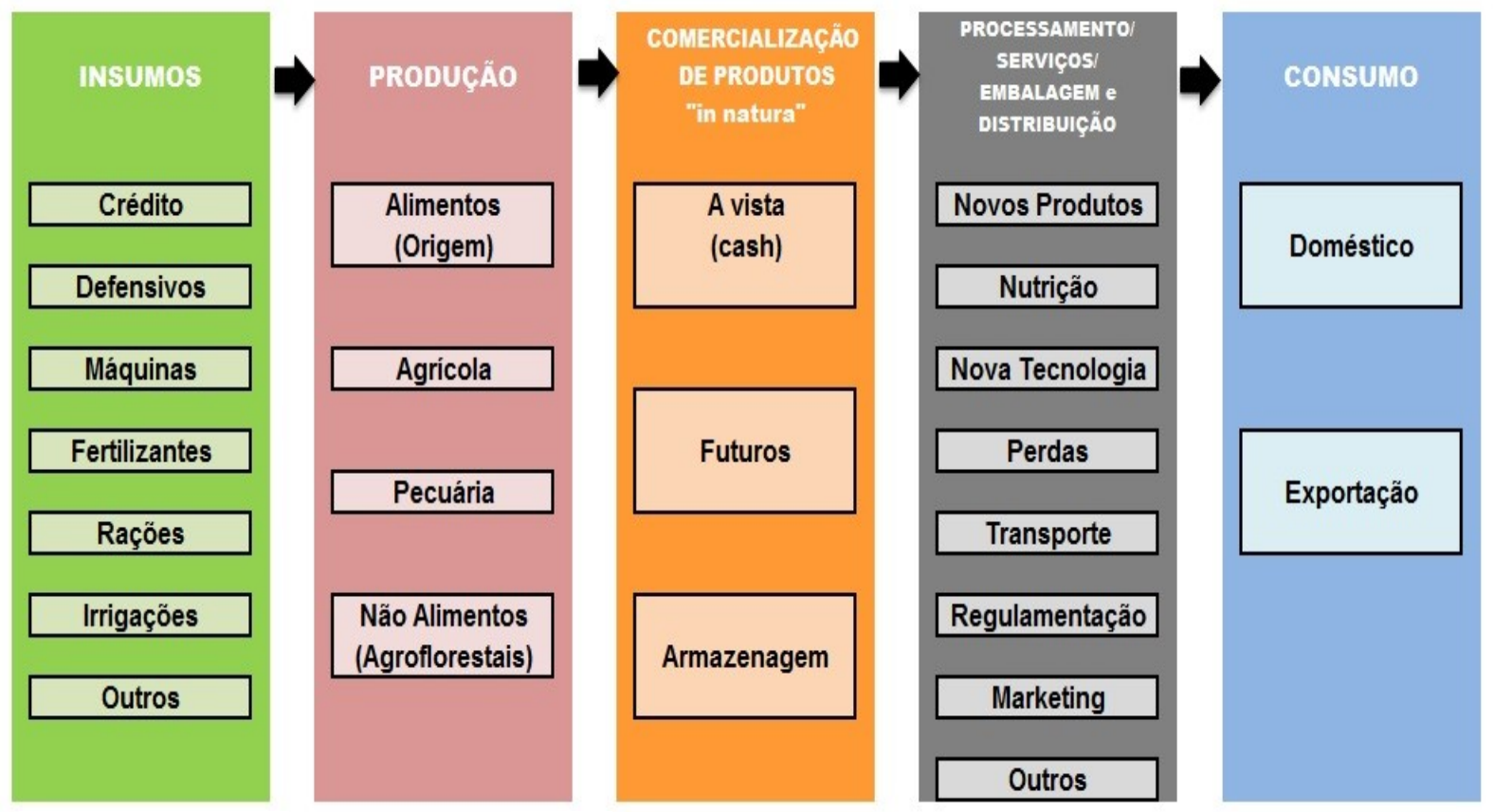

Fonte: adaptado de Henry de Frahan, 1992).

Segundo dados do Cepea (2014), entre 2000 e 2013, o volume exportado pelo agronegócio cresceu e o saldo comercial (receitas das exportações menos gastos com importações) mais que quintuplicou, com crescimento de $468 \%$, conforme é apresentado no gráfico 1.

Gráfico 1 - Evolução do Saldo Comercial do Agronegócio Brasileiro

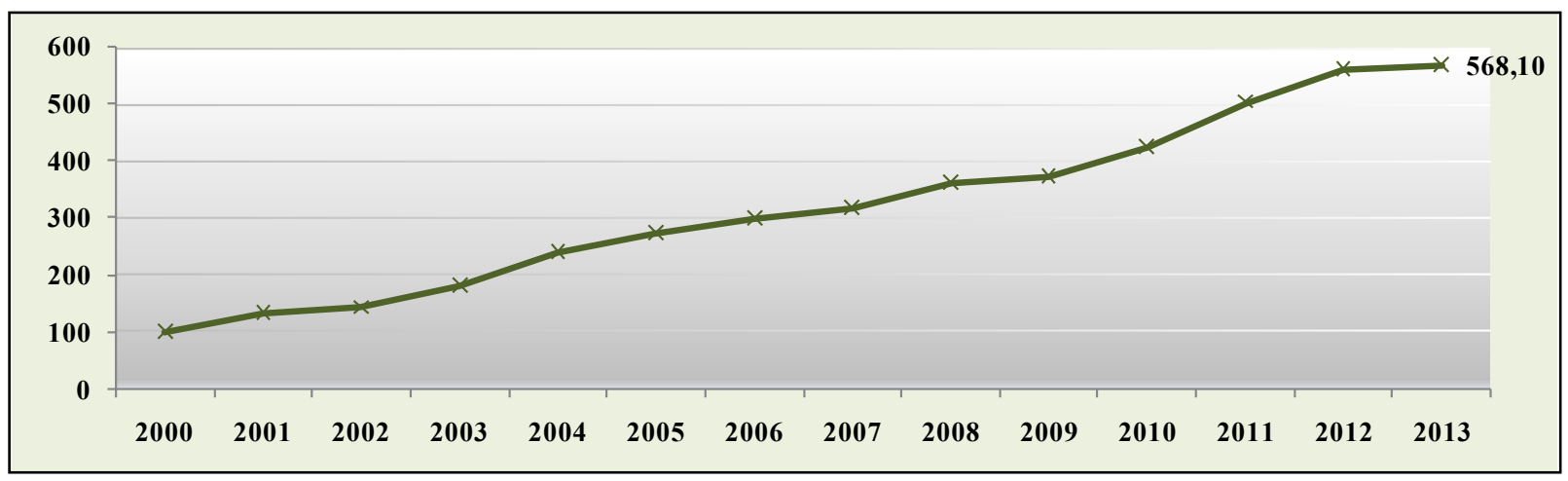

Fonte: Cepea/Esalq-USP (2014).

Revista Eletrônica de Estratégia \& Negócios, Florianópolis, v.8, n.3, set./dez. 2015. 
Dada a relevância do setor, há vários órgãos voltados ao estudo, pesquisa, apoio e regulamentações específicas, entre eles o Cepea, que elabora indicadores de preços de produtos, insumos e de serviços que buscam refletir, com precisão, o movimento do mercado físico; a Associação Brasileira de Agronegócio (Abag), que busca dar suporte aos elos da cadeia produtiva do agronegócio; a Empresa Brasileira de Pesquisa Agropecuária (Embrapa), que estuda soluções de inovação tecnológica e sustentabilidade para agropecuária e agricultura brasileira; entre outros institutos que operam ligados a este ramo da economia (CAMPANHOLA, 2005; GASQUES et al., 2004).

Na esfera governamental, o Ministério da Agricultura, Pecuária e Abastecimento (Mapa), juntamente com outros órgãos, atua no sentido de subsidiar custeios e viabilizar políticas de estímulo ao crescimento e distribuição de linhas de crédito. O agronegócio é o setor que mais exporta, respondendo por mais de $40 \%$ do volume das comercializações totais brasileiras. Em uma apuração do Ministério do Desenvolvimento, Indústria e Comércio Exterior (MDIC, 2014), a maior parcela está entre China e Brasil, seguidos pela Europa e Estados Unidos, conforme pode ser visualizado no gráfico 2.

Gráfico 2 - Principais Destinos das Exportações do Agronegócio Brasileiro em 2013, de Acordo com o Valor Exportado

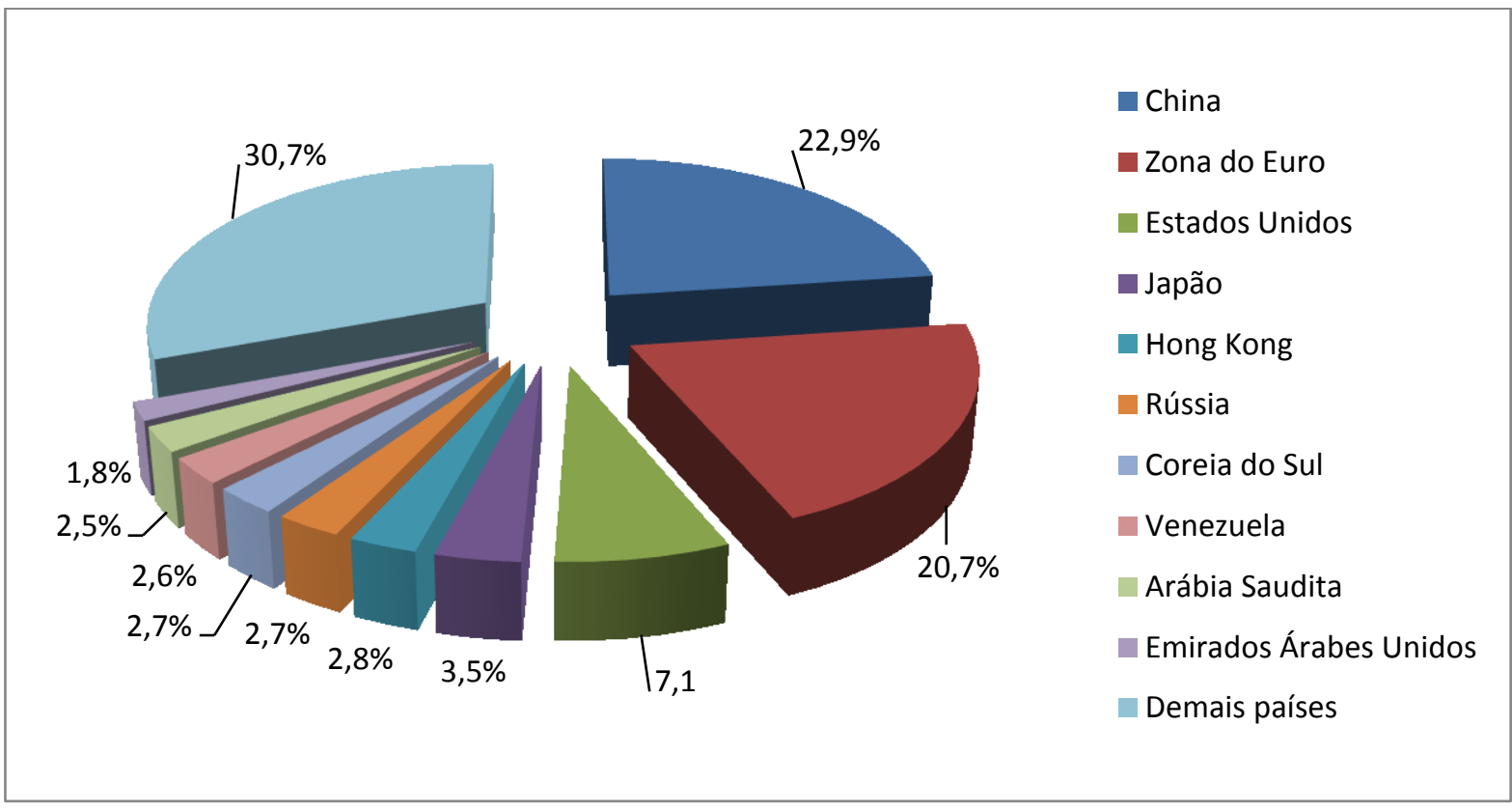

Fonte: Ministério do Desenvolvimento, Indústria e Comércio Exterior (2013).

Revista Eletrônica de Estratégia \& Negócios, Florianópolis, v.8, n.3, set./dez. 2015. 
Ao longo dos anos, o setor cresceu e modificou-se, necessitando cada vez mais de produtos e serviços que estão além das propriedades rurais. Nota-se a necessidade de maiores armazéns, pesquisas, fertilizantes e novas técnicas de cultivo. Tudo isso contribuiu para que o agronegócio brasileiro viesse abastecer também o mercado externo, o que trouxe benefícios e desafios.

\subsection{SEGMENTOS DA CADEIA PRODUTIVA DO AGRONEGÓCIO}

A análise da cadeia produtiva permite visualizar as ações e inter-relações entre todos os envolvidos que participam do segmento. Fazem parte do sistema da cadeia produtiva do agronegócio, cinco principais setores: fornecedores de insumos e bens de produção, produção agropecuária, processamento e transformação, distribuição e consumo, e serviços de apoio (MENDES, 2007).

Um dos segmentos dessa cadeia produtiva, que tem se destacado, é o processamento agroindustrial dos estabelecimentos de pequeno porte (em geral, familiares) que processam produtos agroalimentares com vistas especificamente à comercialização. São definidos pela literatura como agroindústria rural de pequeno porte (GUINDANI, 2011). Em uma definição normativa, tem-se que:

Agroindústria rural se refere às atividades de transformação e beneficiamento de produtos agropecuários de origem animal ou vegetal, que foram realizadas em instalações próprias, comunitárias ou de terceiros, a partir de matéria-prima produzida no próprio estabelecimento agropecuário ou adquirida de outros produtores, desde que a destinação final do produto tivesse sido dada pelo produtor (IBGE, 2006, p. 31).

Observando todos os segmentos integrantes do agronegócio, é pertinente descrever a agroindústria rural, uma vez que ela exemplifica com riqueza o que é um processo originário do agronegócio.

\subsection{FATORES IMPORTANTES DA AGRICULTURA BRASILEIRA}

Ao longo da história, a agricultura expandiu-se tanto no Brasil, que hoje desempenha um papel de essencial importância para o desenvolvimento do país. A criação de programas de financiamento para custeio, investimento e comercialização foram fundamentais para o apoio da produção agropecuária. Araújo (2007, p. 85) cita, também, "as Revista Eletrônica de Estratégia \& Negócios, Florianópolis, v.8, n.3, set./dez. 2015. 
intervenções do Governo Federal na comercialização de produtos agropecuários, que é feita, sobretudo, pela Conab (2014), atuando com vários instrumentos".

Os mais conhecidos são: a fixação e a garantia de preços mínimos para alguns produtos, os Empréstimos do Governo Federal (EGF), as Aquisições do Governo Federal (AGF), os leilões de estoques, o Programa de Escoamento da Produção (PEP), o Valor de Escoamento de Produto (VEP) e o Mercado de Opções (como, por exemplo, os leilões de café).

O setor agrícola, entretanto, é um dos mais vulneráveis a questões climáticas, econômicas e políticas, que afetam o preço do produto. Confirmando este pressuposto, Marques, Mello e Martines Filho (2006), afirmam que:

[...] o preço observado resulta do embate das forças básicas de oferta e demanda do mercado. Essas forças básicas são representadas principalmente pela oferta e demanda potencial do próprio produto, seus produtos substitutos e complementares, pelo grau de competitividade de sua estrutura de mercado, nível dos estoques existentes, desempenho da exportação e importação, medidas de políticas agrícolas e macroeconômicas que influenciam no comportamento desta variável e outros fatores relevantes. (MARQUES, MELLO, MARTINES FILHO, 2006, p. 256).

Estes são os chamados fatores macroeconômicos que, em alguns momentos, afetam a agricultura, por sua relação com a política cambial, juros e outros aspectos. A respeito disto, pode-se afirmar que o regime de câmbio flutuante, adotado pelo Brasil desde 1999, tem ligação direta com tais oscilações. Muito embora alguns autores defendam que a mudança do câmbio administrado para o flutuante foi uma evolução, na prática não há mercado livre, mas semi-administrado, conforme avalia Fortuna (2010). A fim de exemplificar as oscilações do mercado, o Gráfico 3 apresenta a evolução da cotação da saca de soja (60 kg) no Estado de São Paulo, no período de 2004 a 2014.

$\mathrm{Na}$ análise das variações cíclicas do preço da saca de soja, observa-se que, no período inicial do gráfico 3, de 2004 a 2006, os preços caíram a uma média nacional de $\mathrm{R} \$ 22,00$, e os preços internacionais também apresentaram queda e ficaram abaixo da média histórica do período estudado. Atribui-se à política cambial a principal causa dos prejuízos do setor agropecuário nesse período, porque os produtores adquiriram os insumos com o dólar 
mais elevado e, consequentemente, custos de produção elevados e baixa disponibilidade de recursos para custeio (BRUSCO et al., 2005). Após este período, o preço da soja torna a reagir em 2007, atingindo novamente seu pico em setembro de 2012, quando a média nacional ficou em $\mathrm{R} \$ 75,00$.

Gráfico 3 - Histórico da cotação da saca de soja de 60 kg em São Paulo

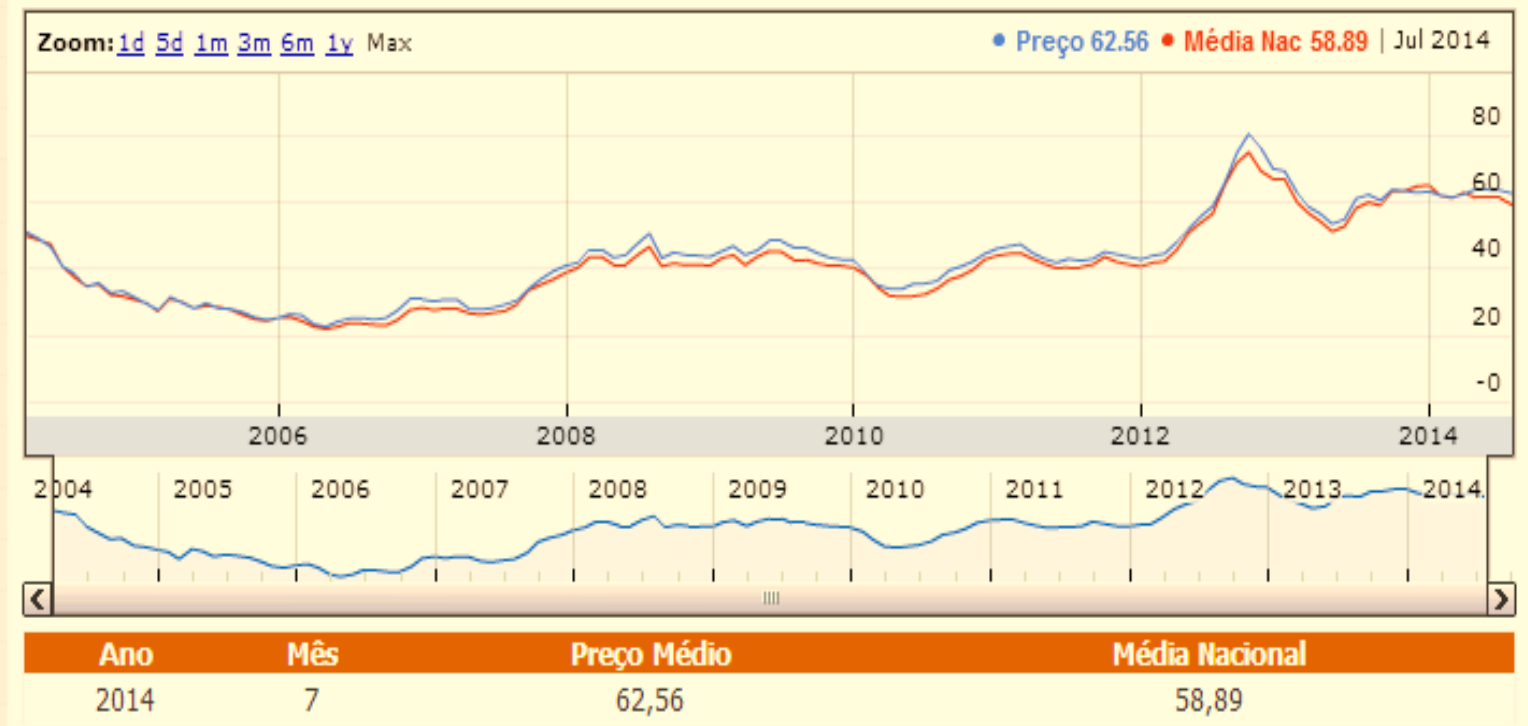

Fonte: Histórico de Cotações (AGROLINK, 2014).

Dadas as dificuldades para custeio, o cooperativismo, presente em muitos estabelecimentos que atuam no setor intermediário do agronegócio, ajuda o agricultor que necessita de capital e insumos. Um instrumento de financiamento presente nesse meio que, segundo pesquisas (ARAÚJO, 2007; BRUSCO et al., 2005; MENDES, 2007), é um dos mais utilizados para custeio da produção, é a CPR (Cédula de Produtor Rural), uma vez que ela facilita a transação entre os envolvidos. Abaixo está o conceito acerca deste instrumento:

A CPR é um instrumento legal (criada pela Lei no 8.929/94) para venda antecipada da produção com entrega futura dos produtos, permitindo ao produtor obter recursos para custeio de suas lavouras. Essa cédula é administrada pela Central de Custódia e de Liquidação Financeira de Títulos (Cetip), entidade autorizada pelo Banco Central. Trata-se de um título cambial (ARAÚJO, 2007, p. 84).

Os produtos agropecuários são produzidos sazonalmente, e a mecanização do campo, as técnicas de agricultura de precisão, o uso de defensivos e fertilizantes mais 
desenvolvidos contribuíram para impulsionar a padronização da produção que, através da redução dos índices de perdas pós-colheita, aumentou a produtividade.

Outro aspecto que desponta no mercado é o incrível crescimento da produtividade das firmas mais capitalizadas, como a BRF (2014), Bunge (2014), Odebrecht (2014) e Cargill (2007), que se destacaram por seus investimentos na área sustentável e pelo seu desempenho e atuação. As boas práticas de gestão realizadas por estas organizações serão discutidas na seção 3 .

\subsection{CADEIA DE VALOR}

A cadeia de valor é a estrutura presente em todas as empresas, que permite a compreensão do fluxo de agregação de valor ao consumidor final, no âmbito de uma ou mais unidades de negócio interdependentes.

As atividades de valor podem ser divididas em dois tipos: atividades primárias e atividades de apoio. De maneira geral, Porter (1989, p. 34) qualifica que "cada atividade de valor emprega insumos adquiridos, recursos humanos (mão-de-obra e gerência) e alguma forma de tecnologia para executar sua função".

Em razão de a cadeia produtiva do agronegócio envolver muitos processos, o autor Araújo (2007) levantou que:

[...] há necessidade de um conceito mais amplo, que englobe todos os segmentos até o produto chegar ao consumidor e que inclua as agregações de valores, as fases de comercialização, a distribuição, etc. Daí surgir, muito recentemente, a ideia de cadeia de valor, como sendo um conceito mais abrangente, que inclua esses segmentos. (ARAÚJO, 2007, p. 23).

Quando se fala em vários processos envolvidos, pode-se citar o estudo de escopo de segmento, que trata da variedade de produtos produzidos que, por consequência, envolve muitas participações na cadeia de valor.

Exemplificando este contexto com a abordagem da agricultura familiar, a agregação de valor ocorre no escopo de segmento. Segundo apuração do Instituto Brasileiro de Geografia e Estatística (IBGE, no censo agropecuário de 2006), a agroindústria rural processa ou beneficia cerca de 30 produtos, os quais incluem desde carvão vegetal, carne fresca, Revista Eletrônica de Estratégia \& Negócios, Florianópolis, v.8, n.3, set./dez. 2015. 
algodão em plumas, arroz descascado e café torrado, até produtos mais tradicionais, como são os casos dos embutidos, queijos, farinhas (de milho e mandioca), panificados, rapadura, doces e geleias. A amplitude desta lista conduz a economias de escopo, além da diversificação da renda rural, que é uma necessidade manifestada pelos agricultores, pelos agentes de desenvolvimento e pelas próprias políticas públicas, como o Pronaf.

Já a economia de escala é obtida, nas etapas da cadeia de valor, com ganhos na negociação e compra de maior volume de matéria-prima, maior volume de produtividade por planta e distribuição, pela redução dos custos logísticos e de propaganda por volume negociado. Dessa forma, para se agregar valor a uma cadeia, é necessário avaliar qual o foco da economia, se de escala ou escopo, e empregar práticas de qualidade no gerenciamento de todo processo.

\section{ESTRATÉGIAS COMPETITIVAS NO AGRONEGÓCIO}

A gestão voltada para criação de valor pode ser usada como ferramenta na tomada de decisões, no momento da formulação da estratégia que contempla análise ambiental, setorial e empresarial, avaliando o desempenho atual e levantando opções estratégicas (GUINDANE et al., 2011). Quanto às escolhas estratégicas, Kluyver (2010) destaca:

As escolhas de posicionamento devem não apenas ditar as atividades que uma empresa escolhe executar e o modo como vai executá-la; devem também especificar como elas se inter-relacionam para formar um conjunto coerente que se diferencie das outras muitas atividades concorrentes. (KLUYVER, 2010, p.5).

O cooperativismo, citado na seção anterior, contribui estrategicamente para imprimir maior grau de competitividade para o grupo de associados, pois compram e comercializam insumos, armazenam e comercializam commodities, e beneficiam ou transformam matérias-primas.

Uma gestão baseada em valor ocorre quando a empresa consegue investir capital a uma taxa de retorno que excede o custo deste capital (COPELAND; KOLLER; MURRIN, 1994). O investimento, como uma das três dimensões estratégicas financeiras relacionadas no quadro 1 , tem por objetivo obter uma taxa de retorno maior que o custo de capital. 
Semelhantemente, Porter $(1989$, p. 2) fala da superação do custo de fabricação no sentido de vantagem competitiva, ao definir que "vantagem competitiva surge fundamentalmente do valor que uma empresa consegue criar para seus compradores e que ultrapassa o custo de fabricação pela empresa".

Quadro 1 - Estratégias Financeiras e Direcionadores de Valor

\begin{tabular}{|l|l|}
\hline \multicolumn{1}{|c|}{ ESTRATÉGIAS FINANCEIRAS } & \multicolumn{1}{c|}{ DIRECIONADORES DE VALOR } \\
\hline \multirow{4}{*}{ Operacionais } & Crescimento de vendas \\
\cline { 2 - 2 } & Giros dos estoques \\
\cline { 2 - 2 } & Margem de lucro \\
\hline \multirow{5}{*}{ Financiamento } & Estrutura de capital \\
\cline { 2 - 3 } Investimento & Custo de capital \\
\cline { 2 - 3 } & Risco financeiro \\
\hline & Investimento em capital de giro \\
\cline { 2 - 3 } & Oportunidades de investimentos \\
\cline { 2 - 3 } & Risco operacional \\
\hline
\end{tabular}

Fonte: Assaf Neto (2010, p. 157).

Analisando cada uma dessas dimensões, pode-se traçar um plano que definirá o posicionamento estratégico que fornecerá as melhores ações diante do contexto de mercado. Kluyver (2010, p. 48) levanta doze tendências globais que julga representarem os desafios mais significativos para as empresas nos próximos 30 anos. Entre tais tendências, a degradação ambiental, a busca por práticas mais sustentáveis e o tratamento de resíduos, segundo o autor, podem contribuir para "aumentar a produção agrícola, enriquecer os alimentos com vitaminas e melhorar os sistemas de distribuição que serão cruciais".

Referente ao desenvolvimento tecnológico, uma estratégia que imprime competitividade é a agricultura de precisão, técnica que consiste no manejo sustentável, na 
qual os insumos (fertilizantes, corretivos e defensivos agrícolas) são distribuídos em taxa variável em cada ponto do campo, onde se identifica a necessidade de cada insumo por meio de mapas de lucratividade, os quais facilitam decisões, como o que produzir e onde produzir, proporcionando a diminuição dos custos de produção e aumento da eficiência com base no manejo diferenciado das áreas.

Além de saber como manejar a terra, é preciso saber manejar a comercialização da produção. Neste sentido, informações sobre o comportamento dos preços e a identificação de variáveis que tenham influência sobre eles tornaram-se particularmente importantes para o êxito nas negociações. A técnica de estocagem para venda posterior é discutida por Mendes (2007, p. 285) através de um exemplo prático, com aplicação da fórmula:

$$
L U C R O_{t}=R T_{t}-C C_{t}-C P_{t}
$$

Onde:

$$
\begin{aligned}
& L U C R O_{t}=\text { lucro se o produto for vendido no mês } t . \\
& R T_{t}=\text { receita total esperada com a venda do produto no mês } t \text {. } \\
& C C_{t}=\text { custo de comercialização e armazenamento no mês } t . \\
& C P_{t}=\text { custo da produção armazenada no mês } t .
\end{aligned}
$$

Em virtude das variáveis do tempo, CP conta com fator de atualização $\left(f_{a}\right)$, dado pela fórmula: $\boldsymbol{f}_{a}=(\mathbf{1 + i})^{n}$, onde:

$$
\begin{aligned}
& i=\text { taxa real de juros mensal (custo de oportunidade) } \\
& n=\text { número de períodos de capitalização, em meses. }
\end{aligned}
$$

O quadro 2, a seguir, apresenta um exemplo prático, trazido pelo autor, para avaliar a viabilidade de manter a produção armazenada a fim de comercializá-la em um determinado período $n$, com aplicação do raciocínio:

$$
\operatorname{LUCRO}_{t+n}>\mathrm{LUCRO}_{t} * f_{a}
$$


Quadro 2 - Exemplo de Cálculo do Retorno Futuro da Comercialização

Exemplo: Um produtor de milho do Paraná necessita saber o custo de oportunidade que viabiliza a armazenagem para venda futura da sua produção. Em março de 2006, mês de colheita, poderia vender a sua produção no mercado físico a $\mathrm{R} \$ 11,00$ por saca de $60 \mathrm{~kg}$. 0 produtor espera que em novembro de 2006 o preço seja de $R \$ 13,20$. O custo de armazenagem estimado é da ordem de R\$0,10 por saca por mês. Qual é a taxa de juros que viabiliza a armazenagem?

$$
\begin{gathered}
\mathbf{P}_{\text {NOVEMBRO 2006 }}=P_{\text {MARÇO } 2006} \times(1+i)^{n}+C C \\
13,20=11,00 \times(1+i)^{8}+(0,10 \times 7) \\
i=1,61 \% \text { ao mês }
\end{gathered}
$$

Caso esse produtor consiga aplicar o valor correspondente à venda da produção de milho em uma alternativa financeira que renda mais de 1,61\% ao mês, é melhor vender a produção à vista na época da colheita e aplicar o dinheiro; do contrário, deverá armazenar o produto para venda futura.

Fonte: Mendes (2007, p. 285).

Compreendendo essa mecânica do mercado, a Cargill (2007) adotou um instrumento chamado Garantia Plus, apresentado em seu relatório institucional de 2007, como uma forma de gerenciamento de risco para seus fornecedores, em razão do instrumento diminuir a volatilidade do mercado. Com a Garantia Plus, seus fornecedores passaram a comprar com preço pré-fixado, mas com a possibilidade de ganho em caso de alta no mercado internacional.

E na ausência ou indisponibilidade de uma opção como essa, o Governo Federal possui diversos programas e instrumentos voltados à comercialização que, em segundo plano, fazem parte de um planejamento político de administração. Tais instrumentos são apresentados no quadro 3, que detalha suas condições e acesso.

Quando a crise na economia acirrou-se em meados de 2008, as tradings, que tradicionalmente financiam a produção, saíram do mercado, e os bancos aumentaram suas exigências. Nesse momento, qualquer iniciativa do Governo (isto é, qualquer instrumento de comercialização) que garantisse o preço era bem-vinda.

Revista Eletrônica de Estratégia \& Negócios, Florianópolis, v.8, n.3, set./dez. 2015. 
Dentre essas escolhas, vale ressaltar que o contrato de opção não dá direito a um financiamento automático à estocagem do produto. Entretanto, a posse do contrato facilita a obtenção do financiamento (EGF, por exemplo), tendo em vista que representa, para o agente financeiro, um cliente de menor risco, por haver garantia antecipada de venda de seu produto (IPEA, 2010).

Quadro 3 - Síntese dos Instrumentos de Comercialização em uso pelo Governo Federal

\begin{tabular}{|c|c|c|}
\hline Instrumento & Condições & Acesso \\
\hline $\begin{array}{l}\text { Aquisição do Governo } \\
\text { Federal (AGF) }\end{array}$ & $\begin{array}{l}\text { 1. Produto posto em armazém credenciado pela Companhia } \\
\text { Nacional de Abastecimento (Conab). } \\
\text { 2. Produto limpo, seco e classificado. }\end{array}$ & $\begin{array}{l}\text { 1. Por intermédio da Conab ou agência local } \\
\text { do Banco do Brasil. } \\
\text { 2. Disponível para produtores e } \\
\text { cooperativas. }\end{array}$ \\
\hline $\begin{array}{l}\text { Empréstimo do Governo } \\
\text { Federal sem opção de } \\
\text { venda (EGF/SOB) }\end{array}$ & $\begin{array}{l}\text { 1. O produto deve ser colocado em armazém credenciado, à } \\
\text { ordem do banco credor. } \\
\text { 2. O valor do empréstimo é calculado de acordo com o valor } \\
\text { do produto em garantia, calculado pelo preço mínimo. }\end{array}$ & $\begin{array}{l}\text { 1. Por intermédio do agente financeiro } \\
\text { interessado em operar com a PGPM. } \\
\text { 2. Disponível para produtores e } \\
\text { cooperativas. }\end{array}$ \\
\hline EGF - indústria & $\begin{array}{l}\text { 1. Contrato de EGF entre o setor de processamento e o } \\
\text { agente financeiro. } \\
\text { 2. O limite de financiamento é de } 50 \% \text { da capacidade de } \\
\text { produção. } \\
\text { 3. Comprovar o pagamento de, pelo menos, o preço mínimo } \\
\text { ao produtor. } \\
\text { 4. Produtos amparados pela PGPM, exceto arroz e soja. }\end{array}$ & $\begin{array}{l}\text { 1. Por intermédio de contato direto entre o } \\
\text { produtor/cooperativa e o processador/ } \\
\text { industrial interessado. } \\
\text { 2. Cooperativa que possui unidade de } \\
\text { processamento de matéria-prima. }\end{array}$ \\
\hline $\begin{array}{l}\text { Prêmio para } \\
\text { escoamento do produto } \\
\text { (PEP) }\end{array}$ & $\begin{array}{l}\text { 1. O Governo Federal, por intermédio da Conab, faz leilão } \\
\text { público de um prêmio para compradores do produto. } \\
\text { 2. Os compradores devem contatar produtores dispostos a } \\
\text { venderem sua produção ao preço mínimo. } \\
\text { 3. Os compradores devem transportar o produto para } \\
\text { destinos previamente estabelecidos pelo programa. }\end{array}$ & $\begin{array}{l}\text { 1. Por intermédio de programas definidos } \\
\text { pelo Ministério da Agricultura e Conab. } \\
\text { 2. O produtor interessado, quando houver } \\
\text { um programa em sua região, deve encontrar } \\
\text { um comprador que tenha arrematado um } \\
\text { lote nos leilões da Conab. }\end{array}$ \\
\hline
\end{tabular}

Revista Eletrônica de Estratégia \& Negócios, Florianópolis, v.8, n.3, set./dez. 2015. 


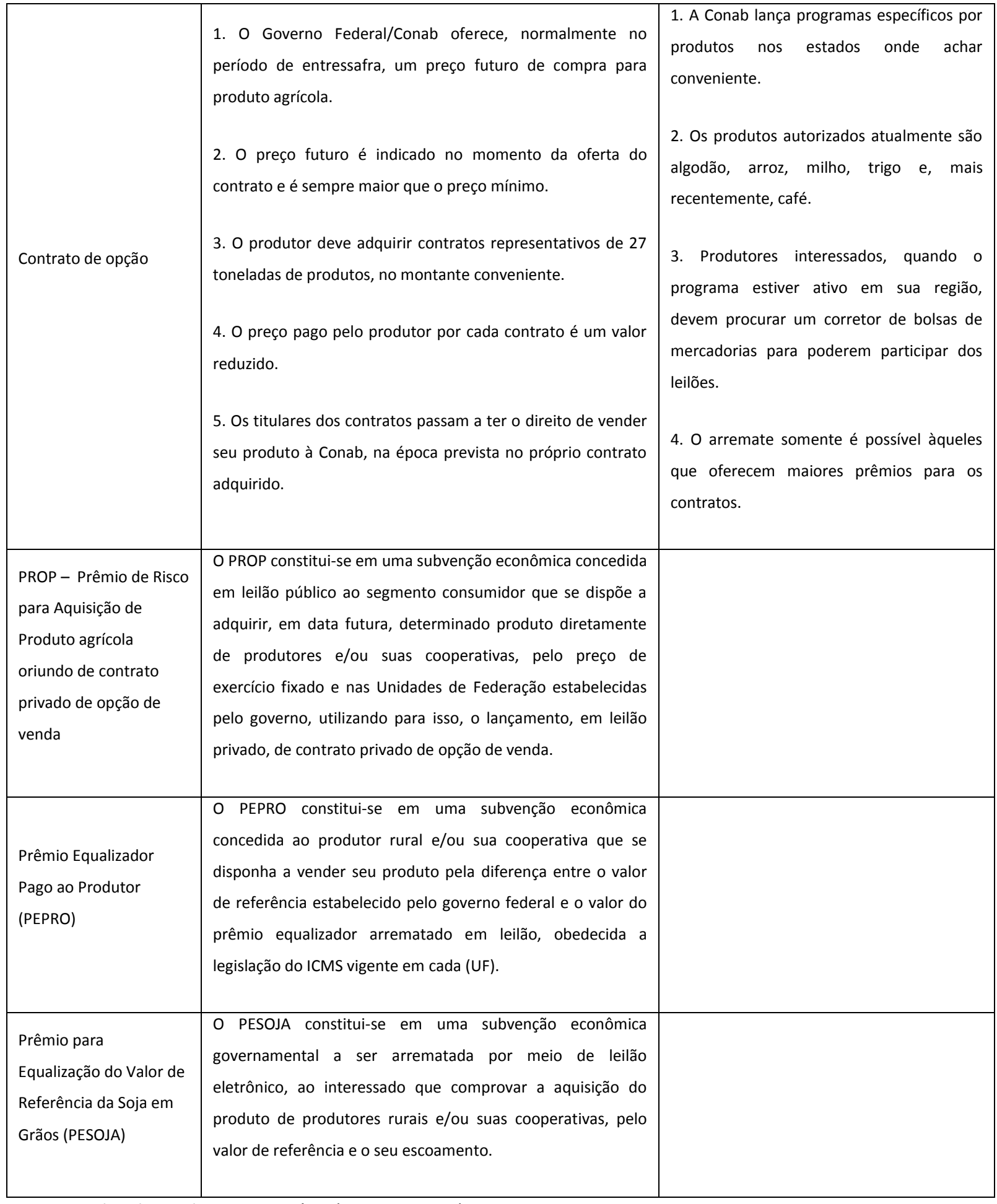

Fonte: Indicadores da Agropecuária (CONAB, 2014).

Em uma apuração realizada pelo Banco Central (Bacen), pode-se ver que a demanda por recursos de custeio de produção tem uma elevação constante, enquanto contratos para investimento e comercialização são bastante instáveis, ao longo dos anos de 2000 a 2012. A tabela 1, proveniente desta apuração do BACEN, engloba separadamente os montantes de cada modalidade de financiamento.

Revista Eletrônica de Estratégia \& Negócios, Florianópolis, v.8, n.3, set./dez. 2015. 
Tabela 1 - Crédito Rural concedido para financiamento de produtores e cooperativas

\begin{tabular}{|c|c|c|c|c|c|c|c|c|}
\hline \multicolumn{9}{|c|}{ Valores em R\$̦ Milhões } \\
\hline \multirow{2}{*}{ ANO } & \multicolumn{2}{|c|}{ Custeio } & \multicolumn{2}{|c|}{ Investimento } & \multicolumn{2}{|c|}{ Comercialização } & \multicolumn{2}{|c|}{ Total } \\
\hline & Contratos & Valor & Contratos & Valor & Contratos & Valor & Contratos & Valor \\
\hline 2000 & 1.050 .789 & 8.918 .799 & 269.941 & 2.334 .905 & 28.504 & 2.525 .799 & 1.349 .234 & 13.779 .503 \\
\hline 2001 & 1.070 .231 & 10.596 .071 & 370.817 & 3.710 .457 & 27.864 & 3.635 .591 & 1.468 .912 & 17.942 .118 \\
\hline 2002 & 1.202 .708 & 13.574 .320 & 492.415 & 4.850 .336 & 23.638 & 4.018 .667 & 1.718 .761 & 22.443 .323 \\
\hline 2003 & 1.439 .720 & 18.950 .986 & 633.638 & 7.113 .971 & 26.982 & 5.037 .725 & 2.100 .340 & 31.102 .682 \\
\hline 2004 & 1.605 .834 & 23.261 .647 & 1.075 .075 & 8.949 .809 & 64.678 & 8.235 .028 & 2.745 .587 & 40.446 .484 \\
\hline 2005 & 1.635 .119 & 23.273 .137 & 1.520 .395 & 9.298 .757 & 87.801 & 9.403 .704 & 3.243 .315 & 41.975 .598 \\
\hline 2006 & 1.479 .812 & 24.366 .560 & 1.982 .073 & 10.131.341 & 60.670 & 9.267 .666 & 3.522 .555 & 43.765 .567 \\
\hline 2007 & 1.414 .936 & 30.603 .305 & 1.504 .754 & 1.090 .877 & 45.295 & 9.652 .649 & 2.964 .985 & 51.164 .725 \\
\hline 2008 & 1.388 .235 & 39.340 .867 & 997.539 & 14.268 .455 & 49.508 & 12.562 .776 & 2.435 .282 & 66.172 .098 \\
\hline 2009 & 1.414 .290 & 42.838 .595 & 1.024 .994 & 17.549 .269 & 66.570 & 14.798 .283 & 2.505 .854 & 75.186 .147 \\
\hline 2010 & 1.232 .431 & 45.809 .467 & 1.037 .987 & 20.926 .120 & 65.792 & 15.340 .975 & 2.336 .210 & 82.076 .562 \\
\hline 2011 & 1.135 .825 & 51.528 .608 & 1.040 .161 & 23.138 .221 & 96.575 & 15.899 .574 & 2.272 .561 & 90.566 .404 \\
\hline 2012 & 1.159 .134 & 62.949 .248 & 1.442 .566 & 35.056 .094 & 45.031 & 16.840 .957 & 2.646 .731 & 114.846 .300 \\
\hline
\end{tabular}

Fonte: Bacen (2012).

De acordo com o gráfico 4, elaborado a partir dos dados da Tabela 1, nota-se uma queda do volume de contratos de investimento em 2007. Tal queda foi ocasionada pelo aumento do preço do petróleo e de seus derivados, por mudanças climáticas, e pelo aumento da utilização de cereais para a produção de biocombustível, que levaram à eclosão dos preços dos produtos agrícolas naquele ano. Assim, os produtores procuraram, em maior 
escala, contratos para custeio e comercialização de sua produção, ao invés de empregar investimentos em infraestrutura e tecnologia.

No segmento depois da porteira, onde se encontram as agroindústrias, destacam-se muitos exemplos de práticas sustentáveis. A Bunge, em 2009, inaugurou uma unidade em Nova Mutum (MT), onde fez um trabalho rígido de recuperação e tratamento de todo efluente de dentro da planta. Criou, também, uma reserva ambiental em uma área de 70 hectares. A BRF, outra grande empresa do setor, também mantém, em todas as suas unidades fabris, Estações de Tratamento de Efluentes (ETE) para que a água possa ser devolvida ao meio ambiente sem alterar a classe do corpo receptor. E a Odebrecht (2014), outra organização de destaque, realiza o processamento da maior parte dos resíduos gerados no processo industrial, transformando-os em subprodutos, que são reintegrados ao ciclo produtivo.

Gráfico 4 - Índice de elevação do volume em (r\$) dos créditos concedidos para produtos e cooperativas

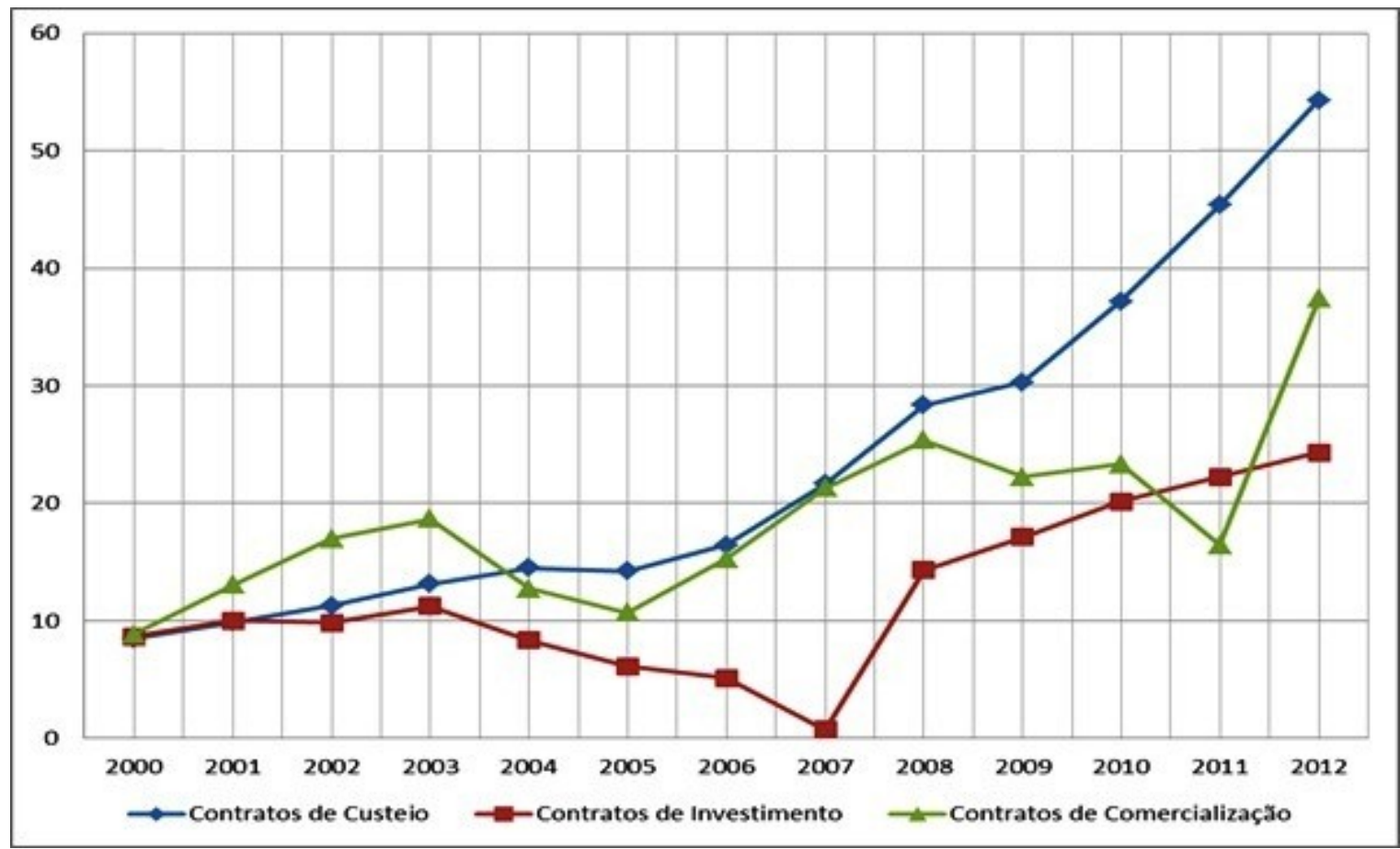

Fonte: elaboração própria a partir de dados do Bacen (2012). 
Estas e outras iniciativas de empresas, reconhecidas como modelos, contribuem para que outras organizações atuantes nesse mercado também trabalhem em iniciativas que valorizem a preservação e conservação dos recursos hídricos e do solo.

\subsection{ANÁLISE SWOT DO AGRONEGÓCIO}

Este é um tipo de análise que consiste na delimitação de cenários, que surge da necessidade de medir desempenhos. 0 quadro 4, a seguir, foi elaborado com base nos dados da pesquisa.

Com a definição do cenário, deve haver a formulação da estratégia competitiva (ANDREWS, 1965). Os cenários enfatizam as incertezas presentes na indústria. Acerca disso, Porter (1989) esclarece que

Incertezas com pouca probabilidade de ocorrência, mas com um impacto potencialmente grande sobre a estrutura, também não devem ser negligenciadas. Cada tendência ou mudança possível é então analisada para determinar se ela poderia ter um impacto significativo sobre a estrutura industrial, e o grau de incerteza de previsão de seu impacto. Este tipo de procedimento costuma produzir uma relação de incertezas que mistura causa e efeitos. (PORTER, 1989, p. 416).

Quadro 4 - Diagrama SWOT do Agronegócio

\begin{tabular}{|c|c|c|}
\hline \multirow{8}{*}{ 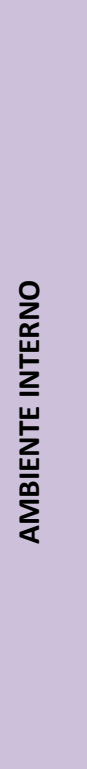 } & FORÇAS & FRAQUEZAS \\
\hline & Cooperativismo & Insuficiência de recursos e escassez de caixa \\
\hline & Novos equipamentos com mais tecnologias & Defasagem tecnológica \\
\hline & Aplicação de novas variedades de insumos & Altos custos com transporte a armazenagem \\
\hline & Adoção de programas de garantia de qualidade (ISO) & Baixa especialização para atender o mercado \\
\hline & Produção diversificada & Variabilidade de produção \\
\hline & Evolução dos meios de financiamento & Baixos níveis de estoque \\
\hline & Marca consolidada no mercado & Pouca ou nenhuma prática de sustentabilidade \\
\hline \multirow{2}{*}{ 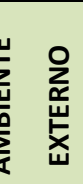 } & OPORTUNIDADES & AMEAÇAS \\
\hline & Aumento da demanda por alimentos & Condições Climáticas \\
\hline
\end{tabular}

Revista Eletrônica de Estratégia \& Negócios, Florianópolis, v.8, n.3, set./dez. 2015. 


\begin{tabular}{|l|l|l|} 
Cotação do dólar em alta & Pragas e doenças \\
\cline { 2 - 3 } & Preços atrativos e competitivos & Oscilação do preço das commodities \\
\cline { 2 - 3 } & Programas de subsídio do governo & Legislação ambiental mais rígida \\
\hline Surgimento de linhas de crédito mais acessíveis & Recessões e inflação \\
\hline Aumento do poder aquisitivo da população & Concorrência forte das firmas mais capitalizadas \\
\hline Mecanização do campo & Falta de mão de obra especializada \\
\hline
\end{tabular}

Fonte: elaborado pelos autores.

Este diagrama engloba aspectos da cadeia produtiva do agronegócio como um todo. Entretanto, existem pontos fortes observados com maior predominância em agroindustriais familiares, como é o caso do cooperativismo e da produção diversificada; já as grandes empresas agroindustriais fortificam-se com o emprego de equipamentos com mais tecnologia, adoção de programas de garantia de qualidade (ISO), entre outras técnicas que proporcionem consolidar sua marca no mercado.

Em contrapartida, se, por um lado, alguns pontos do ambiente interno são mais observados em uns segmentos do que em outros, as variáveis do ambiente externo podem afetar ou beneficiar toda a cadeia produtiva. Frequentemente, pesquisas têm divulgado projeções de crescimento e expansão da população mundial, o que acarreta consequente aumento na demanda por alimentos, fator que é, ao mesmo tempo, uma oportunidade e um desafio para produtores que, para acompanhar esta tendência, necessitam não só produzir mais, também melhorar seus índices de produtividade por área plantada. Então. o que fazer? A resposta está na própria ferramenta de análise SWOT, que ajuda a ter clareza do negócio, pois o processo de implementação estratégica demanda o conhecimento de fatores ambientais externos, e a compreensão do ambiente interno que leve a uma avaliação das forças e fraquezas, onde seja possível estabelecer como aproveitar as oportunidades, de acordo com os recursos disponíveis, para alcançar objetivos de médio e longo prazo. Chandler (1962) define esse processo como a determinação dos objetivos básicos de longo prazo de uma empresa e a adoção de ações adequadas, e organização de recursos para atingir objetivos. 


\subsection{A QUALIDADE DO AGRONEGÓCIO NO CAMPO}

A qualidade está envolvida, hoje, com padrões de concorrência que exigem competência e vantagem competitiva no custo e estratégias mercadológicas. A abertura do mercado mundial, ocorrida no Brasil na década de 1990, elevou o patamar de qualidade exigido dos produtos e serviços. Neste sentido, Marshall (2010) relata que

A principal diferença entre a abordagem do início do século XX e a atual é que a qualidade agora está relacionada às necessidades e aos anseios dos clientes. Seja qual for o porte da empresa, observam-se programas de qualidade e melhoria de processos na maioria dos setores econômicos. (MARSHALL, 2010, p. 32).

A prática do Controle da Qualidade Total (TQC) também traz uma abordagem com três objetivos voltados para os desejos dos clientes, que compreendem: planejar, manter e melhorar a qualidade (CAMPOS, 1999, p. 41). Muitas pesquisas buscam analisar os pontos fortes e as prioridades de melhoria dos serviços e produtos oferecidos pelas organizações (DAMKE; SILVA; WALTER, 2011; WALTER et al., 2014; BRF, 2014), destacando a importância do fator qualidade no processo produtivo.

As empresas envolvidas com agronegócio no Brasil deparam-se com exigências de padrões de qualidade cada vez mais rígidos, assim como os produtores que explorarão o potencial da padronização como instrumento de diferenciação de seu produto; e a certificação tem sido um mecanismo preferencial para essa finalidade. No rol das certificações contempladas pelas normas ISO e no segmento de estudo dessa pesquisa, estão a ISO 14000, que trata das questões ambientais e, no setor agrícola, é aplicável principalmente às agroindústrias; a ISO 22000, acerca das questões de segurança dos alimentos; e a ISO 9001, que estabelece requisitos para o Sistema de Gestão da Qualidade (SGQ) de uma organização.

As normas ISO têm um papel importante no mundo globalizado, devido seu reconhecimento internacional. Por isso, em 2009, o Cepea e a BM\&FBOVESPA (2011) deram início ao processo de adequação das etapas de elaboração e divulgação dos indicadores de preço ESALQ/BM\&FBOVESPA do Boi Gordo, Bezerro, Milho e Arroz, às normas da ISO 9001: 2008, com apoio da empresa Lannes \& Hoffmann. A certificação foi concedida pela empresa ABS Quality Evaluations. A obtenção deste selo de reconhecimento internacional foi um Revista Eletrônica de Estratégia \& Negócios, Florianópolis, v.8, n.3, set./dez. 2015. 
marco para o agronegócio brasileiro e representa, para os participantes do mercado, a garantia de qualidade dos processos de coleta, apuração e divulgação diária de preços que são referência para o setor.

Outra preocupação que contribuiu para o emprego das certificações de qualidade foram necessidades ligadas à saúde e higiene dos alimentos. A título de exemplo, a certificação de origem da carne de porco foi impulsionada a partir do momento que surgiram as divulgações, na imprensa, acerca de carnes contaminadas por vaca louca (Encefalopatia Espongiforme Bovina), e o reflexo dessa notícia afetou não só o setor de carne bovina, como o de carne suína, que sentiu queda de $25 \%$ dos preços, na época.

No mercado de grãos, por sua vez, em resposta às exigências por qualidade da semente de soja, a Embrapa Soja promoveu, em dezembro de 2000, o XXVII Curso de Tetrazólio e Patologia de Sementes, apresentando tecnologias adequadas para avaliar corretamente a qualidade das sementes de soja e identificar as causas de descarte de lotes por baixa germinação no teste padrão. Este evento remete ao selo da qualidade que trata da medição dos resultados, que informa se o objetivo foi alcançado ou não (CAMPOS, 1999, p. 14).

A gestão com qualidade contribui para agregar maior valor ao negócio e aprimora processos internos, eleva a satisfação dos clientes e habilita a empresa para se expandir.

\subsection{INDICADORES DE DESEMPENHO DO AGRONEGÓCIO}

A análise dos indicadores identifica o desempenho do setor, e uma gestão eficaz de uma empresa agrícola, como qualquer outra, de qualquer outro ramo de atividade, requer a observação e uso de indicadores.

Devido à amplitude do agronegócio, o delineamento de um segmento na cadeia produtiva requer foco, em virtude de seus elos. À respeito disso, a utilização da Matriz de Insumo-Produto (MIP), desenvolvida pelo economista Wassily Leontief (1986), é um dos indicadores de desempenho ideal, porque permite a identificação da interdependência das atividades produtivas, no que concerne aos insumos e produtos utilizados e decorrentes do processo de produção.

Revista Eletrônica de Estratégia \& Negócios, Florianópolis, v.8, n.3, set./dez. 2015. 
Atualmente, compete ao IBGE a elaboração das MIP brasileiras, cuja abrangência é nacional e periodicidade é quinquenal, sendo a mais recente datada de 2005 (IPEA, 2010). modelo permite obter o valor da produção em cada uma das atividades econômicas, a partir de determinada demanda final.

Outro indicador que possibilita a verificação de tendências e o comportamento da economia é a análise comparativa do saldo da balança comercial brasileira. 0 gráfico 5 refere-se ao saldo da balança comercial brasileira com a comparação entre os meses de janeiro a maio dos anos de 2013 e 2014.

\section{Gráfico 5 - Saldo da Balança Comercial 2013/2014}

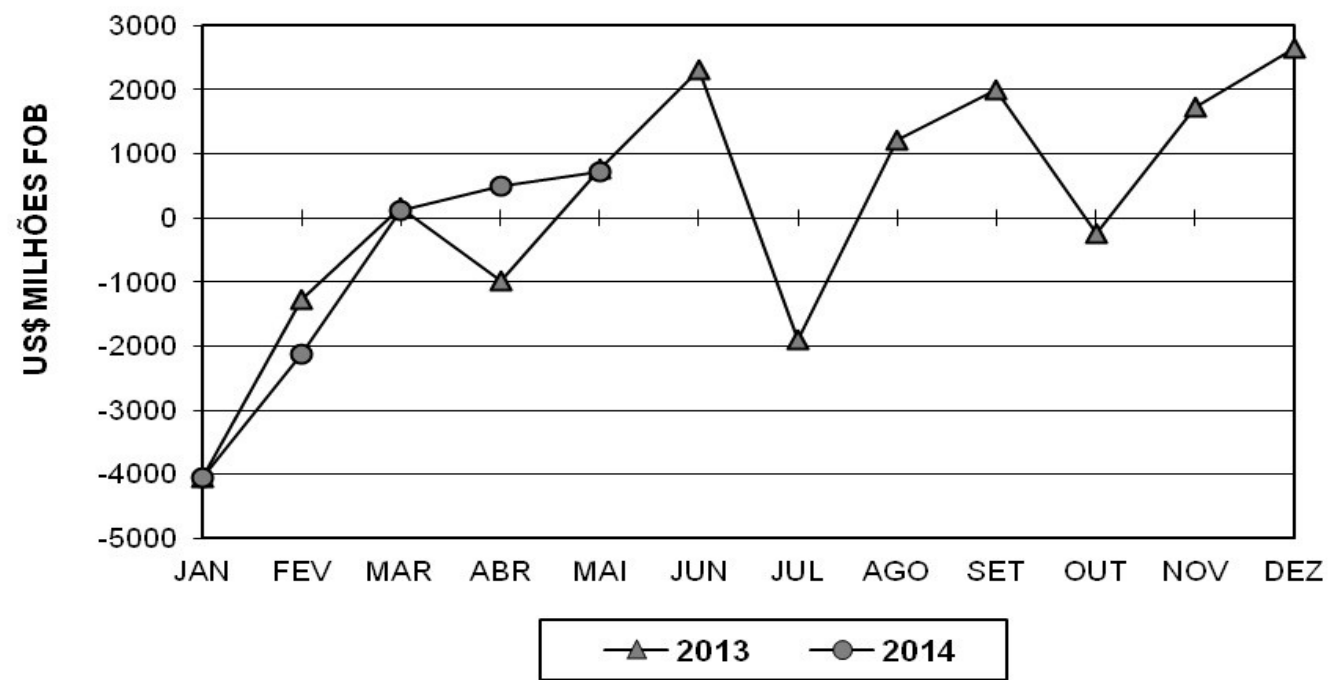

Fonte: MDIC (2014).

No gráfico 5, pode-se observar que em ambos os anos, de 2013 e 2014, a balança comercial ficou superavitária no mês de março; porém, fechou deficitária em abril de 2013, devido ao volume maior de importações ocorridas no período. Diferentemente, em abril de 2014, a balança atingiu superávit de US\$ 0,5 bilhão, e as razões apontadas no relatório do MDIC (2014) são o aumento da exportação de petróleo em $+20 \%$ em volume no quadrimestre; exportação recorde mensal de soja de 8,3 milhões de toneladas; e aumento de exportação para os EUA em + 44,5\%.

A soja é o produto que figura como principal item de exportação do Brasil, e no ano de 2014, a safra esteve bem adiantada em comparação ao ano anterior, segundo dados do 
CEPEA/ESALQ (2014). No Mato Grosso, o Instituto Matogrossense de Economia Agropecuária (Imea) aponta que $71 \%$ da produção do Estado havia sido vendida até o final de abril de 2014, enquanto no Paraná, o Deral/Seab indicou venda de 53\%. O preço médio da soja exportada em abril foi de $\mathrm{R} \$ 67,13 /$ saca de $60 \mathrm{~kg}$, o menor do ano, mas 5,4\% acima da média de abril/2013, de $\mathrm{R} \$$ 63,69/saca de $60 \mathrm{~kg}$, segundo dados da Secretaria de Comércio Exterior (Secex).

Em resumo, a antecipação da safra e a variação de preço foram favoráveis para o fechamento positivo do saldo de abril de 2014, em comparação ao ano de 2013, que alcançou superávit somente no mês de maio. Marques, Mello e Martines Filho (2006) levantam que, na atualidade brasileira, pode-se agrupar em três, os setores mais importantes em termos de análise de mercado do agronegócio: grãos (soja, milho, café), carnes (boi, principalmente) e sucroalcooleiro.

Observando as macrotendências, o volume de aquisição de máquinas e equipamentos também aponta importante indicador de desempenho do setor. Em 2013, o índice de crescimento para máquinas e equipamentos fechou em $7 \%$, uma das melhores taxas de crescimento do setor, conforme levantamento do MDIC (2014), e isso se atribuiu, entre outros fatores, ao crédito mais barato oferecido pelo BNDES no período, à valorização da soja a partir de setembro de 2012 , e o crescimento de $23,8 \%$ da produção no ano seguinte, segundo o IBGE. Com maior lucratividade, os produtores tiveram condições de investir mais em suas lavouras no ano seguinte.

O grau de alavancagem financeira de um negócio, que se refere aos meios que uma instituição utiliza para multiplicar a rentabilidade por meio de endividamento, também corrobora como importante indicador, uma vez que:

Quando intermediários financeiros possuem muito capital, o que equivale a uma baixa alavancagem, eles podem absorver perdas sem que cheguem a falir. Quando possuem pouco capital, entretanto - ou seja, quando estão altamente alavancados, até mesmo pequenas perdas podem levar a falência (BLANCHARD, 2011, p. 539).

Em geral, quanto maior o GAF (Grau de Alavancagem Financeira), mais alto o risco financeiro, por isto a importância de sempre haver o acompanhamento das decisões 
estratégicas de investimento que envolve, em muitos casos, o financiamento com recursos de terceiros. Na sequência, as considerações finais da presente pesquisa são apresentadas.

\section{CONSIDERAÇÕES FINAIS}

O agronegócio é um segmento bastante promissor no Brasil, a produção agrícola sustenta recordes e desponta como principal alicerce da economia, impulsiona o superávit da balança comercial do país, e proporciona mais empregos. Uma das tendências levantadas, conforme Mendes (2007, p. 52), aponta que, em fases de processamento e distribuição, que atualmente giram em torno de US\$ 6,8 trilhões por ano (ou seja, 70\% do valor total do agronegócio), a participação relativa poderá ser aumentada, devendo chegar a gerar ao redor de US\$10,7 trilhões por ano.

Observando estas informações é possível afirmar que, embora alguns segmentos apresentem momentos de dificuldades econômicas, o setor como um todo, e através de seus elos, possui grande potencial de crescimento. Porter (1989) ressalta que, em uma cadeia produtiva, o mercado é representado pelo consumidor, uma vez que cada um dos segmentos é responsável por um elo da cadeia, e que os fatores de desempenho competitivo de uma cadeia são iguais para todos, o que muda é o processo, a cadeia de valor.

O presente artigo buscou descrever os cenários desta cadeia produtiva, considerando estratégias e recursos utilizados dentro de alguns segmentos. Identificou-se que todas as atividades vinculadas ao agronegócio necessitam de estratégias para lidar com a variabilidade de preços, que é um componente de risco no mercado, tanto para produtores quanto para consumidores. Embora não se possa controlar uma alta ou baixa variabilidade de preços, é preciso conhecer os instrumentos presentes no mercado para administração de risco, realização de investimentos e melhor aproveitamento dos recursos existentes.

Para atender as exigências de um mercado global e agregar valor à produção, práticas de sustentabilidade ambiental, incrementos tecnológicos e certificações de qualidade são as estratégias de negócio mais observadas nas agroindustriais. Aliados a estas iniciativas, estas grandes empresas do setor buscam obter economias de escala; e os Revista Eletrônica de Estratégia \& Negócios, Florianópolis, v.8, n.3, set./dez. 2015. 
produtores de insumos tendem a fazer uso de economias de escopo, com a diversificação da produção, que é uma técnica frequente nesse meio, em razão da instabilidade do mercado, e às dificuldades para financiamento da produção, a despeito de hoje haver maior disponibilidade de linhas de crédito rural e programas governamentais com este propósito do que antigamente. Araújo (2007, p. 46) coloca que os financiamentos aos agropecuaristas são mais comumente realizados por bancos estatais e por empresas interessadas na compra futura de produtos oriundos da agropecuária; em geral, são agroindústrias interessadas em assegurar o abastecimento de matérias-primas a suas fábricas.

Os resultados dos investimentos em pesquisas e tecnologias em insumos agropecuários são obtidos em longo prazo. E a mecanização do campo impulsiona a padronização da produção, reduzindo índices de perdas pós-colheita, trazendo aumento de produtividade, entre outros ganhos.

A cultura de investimentos em recursos para tecnologia e inovação precisa ser mais trabalhada no Brasil. Segundo Mendes (2007, p. 154), em 2003, o Brasil investiu apenas 0,1\% do PIB da agropecuária em pesquisas, enquanto, nos Estados Unidos, a média de investimento é de $1,5 \%$ ao ano.

Para que o agronegócio continue a dar bons frutos, o setor precisa, sobretudo, de investimentos que proporcionem padrões mais elevados de qualidade e maior rentabilidade aos envolvidos. 


\section{REFERÊNCIAS}

AGROLINK. Histórico de cotações. Disponível em:

<http://www.agrolink.com.br/cotacoes/Historico.aspx?e=9847\&p=9\&l=14904> Acesso em: 8 jul. 2014.

ANDREWS, K. R. The concept of corporate strategy. Homewood, IL: Richard D. Irwin, 1965.

ARAÚJO, J. M. Fundamentos de agronegócios. 2. ed. São Paulo: Atlas, 2007.

ASSAF NETO, A. Finanças corporativas e valor. 5. ed. São Paulo: Atlas, 2010.

BACEN. BANCO CENTRAL. Anuário estatístico de crédito rural - 2012. Disponível em: <http://www.bcb.gov.br/htms/creditorural/2012/produtCooper.asp?idpai=RELRURAL2012>. Acesso em: 15 jul. 2014.

BACHA, C. J. C. Economia e política agrícola no Brasil. São Paulo: Atlas, 2004.

BLANCHARD, O. Macroeconomia. 5. ed. São Paulo: Pearson Prentice Hall, 2011.

BMF\&BOVESPA. Cepea e BM\&FBOVESPA obtêm ISO 9001 para indicadores de preço do agronegócio. Disponível em: <http://www.bmfbovespa.com.br/pt-br/noticias/2011/Cepeae-BMFBOVESPA-obtem-ISO-9001-para-indicadores-de-preco-do-agronegocio>. Acesso em: 10 jul. 2014.

BRF. BRASIL FOODS S.A. Governança corporativa: sustentabilidade. Disponível em: <http://www.brasilfoods.com/ri/siteri/web/conteudo>. Acesso em: 10 jul. 2014.

BRUSCO, J.; SOUZA, E. G.; RODRIGUES JR., F. A.; JOHANN, J. A.; PEREIRA, J. O. Mapas de lucratividade da soja em sistemas de cultivo agricultura de precisão e cultivo convencional. In: SIMPÓSIO INTERNACIONAL DE AGRICULTURA DE PRECISÃO, 3., Sete Lagoas, MG. Anais... Sete Lagoas, MG: 2005.

BUNGE. Sustentabilidade na cadeia de valor. Disponível em:

<http://www.bunge.com.br/sustentabilidade>. Acesso em: 10 jul. 2014.

CAMPANHOLA, C. “A inovação tecnológica frente aos desafios do agronegócio”. São Paulo: 02 jan. 2005. Disponível em: <http://www.agronline.com.br/artigos/artigo.php?id=196>. Acesso em: 05 jul. 2014.

CAMPOS, V. F. TQC - controle da qualidade total (no estilo japonês). Belo Horizonte, MG: Editora de Desenvolvimento Gerencial, 1999.

CARGILL, Relatório anual 2007. Disponível em: <http://www.cargill.com.br/wcm/groups/public/@csf/@brazil/documents/document/br2007-annual-rpt.pdf >. Acesso em: 21 jul. 2014 
referência: abr. 2014. Disponível em:

<http://cepea.esalq.usp.br/agromensal/2014/04_abril/Soja.htm>. Acesso em: 11 jul. 2014.

CHANDLER, A. D. Strategy and structure. Cambridge, MA: MIT Press, 1962.

CONAB. COMPANHIA NACIONAL DE ABASTECIMENTO. Comercialização - indicadores da agropecuária. Disponível em: <http://www.conab.gov.br/conteudos.php?a=1523\&t=1>. Acesso em: 12 jul. 2014.

COPELAND, T.; KOLLER, T.; MURRIN, J. Valuation - measuring and managing the value of companies. NewYork: Wiley Frontiers in Finance, 1994.

DAMKE, E. J.; SILVA, E. D.; WALTER, S. A. Sistemas de controle e alinhamento estratégico: proposição de indicadores. Revista Eletrônica de Estratégia \& Negócios, v. 4, n. 1, p. 65-87, 2011.

FORTUNA, E. Mercado financeiro: produtos e serviços. 18. ed. Rio de Janeiro: Qualitymark, 2010.

GASQUES, J. G. ; REZENDE, G. C. ; VERDE, C. M. V. ; SALERMO, M. S. ; CONCEIÇÃO, J. C. P. R.; CARVALHO, J. C. S. Desempenho e crescimento do agronegócio no Brasil. IPEA, Brasília, fevereiro de 2004. (Texto para Discussão no 1009).

GUINDANI, A. A.; GUINDANI, R. A.; CRUZ, A. W.; MARTINS, T. S. Planejamento estratégico orçamentário: série administração estratégica. Curitiba: IBPEX, 2011.

HENRY DE FRAHAN, B. Global agribusiness education and curriculum relevancy and challenges : the relevancy to european agribusiness and food industries in Europe. In: SYMPOSIUM OF THE INTERNATIONAL ASSOCIATION OF AGROBUSINESS MANAGEMENT: Evolution of the Food Chain in a Changing International Environment, 2nd. Oxford, Proceedings... Oxford: 1992, Maio 16-19. Disponível em:

<http://hdl.handle.net/2078.1/73557>. Acesso em: 15 jul. 2014.

IBGE. INSTITUTO BRASILEIRO DE GEOGRAFIA E ESTATÍSTICA. Censo agropecuário de 2006. Disponível em: <http://www.ibge.gov.br/>. Acesso em: 12 jul. 2014.

IPEA. INSTITUTO DE PESQUISA ECONÔMICA APLICADA. Brasil em desenvolvimento: estado, planejamento e políticas públicas. Vol. II. Série: Brasil: o estado de uma nação. Brasília: Ipea, 2010.

KLUYVER, C. A. Estratégia: uma visão executiva. 3. ed. São Paulo: Pearson Prentice Hall, 2010.

LEONTIEF, W. Input-output economics. 2. nd. New York: Oxford University Press, 1986.

MARQUES, P. V.; MELLO, P. C.; MARTINES FILHO, J. G. Mercados futuros e de opções agropecuárias. Piracicaba/SP, Departamento de Economia, Administração e Sociologia da ESALQ/USP, 2006, Série Didática no D-129.

MARSHALL, I. J. Gestão da qualidade. 10. ed. Rio de Janeiro: Editora FGV, 2010.

Revista Eletrônica de Estratégia \& Negócios, Florianópolis, v.8, n.3, set./dez. 2015. 
MENDES, J. T. G. Agronegócio: uma abordagem econômica. São Paulo: Pearson Prentice Hall, 2007.

MDIC. MINISTÉRIO DO DESENVOLVIMENTO, INDÚSTRIA E COMÉRCIO EXTERIOR. Balança comercial brasileira: mensal. Disponível em:

<http://www.mdic.gov.br/sitio/interna/interna.php?area=5\&menu=1161>. Acesso em: 12 jul. 2014.

ODEBRECHT Agroindustrial. Relatório anual de safra 2012-2013. Disponível em:

<http://www.odebrechtagroindustrial.com/sites/default/files/relatoriosanuais/ra_safra_201 2-2013.pdf>. Acesso em: 10 jul. 2014.

PORTER, M. E. Vantagem competitiva: criando e sustentando um desempenho superior. Trad. Elizabeth Maria de Pinto Braga. 13. ed. Rio de Janeiro: Campus Elsevier, 1989.

WALTER, S. A.; TONTINI, G.; ANDRADE, K. A.; BACH, T. M. Qualidade percebida de stakeholders como estratégia de melhoria dos serviços. Revista Eletrônica de Estratégia \& Negócios, v. 7, n. 1, p. 3-28, 2014. 